\title{
Moment Curvature Analysis of RC Column as per IS 456:2000
}

\author{
Pramodini Naik Gaonkar and Dr. Satish A. Annigeri
}

\begin{abstract}
The current seismic design practice stops at demand estimation, analysis and design and consequently cannot guarantee that the designed structure meets the objectives set at the start. Performance based design (PBD), which involves performance evaluation and redesign if necessary, is a better approach to structural design. Most inelastic analysis methods assign point plasticity at section locations where plastic deformations are most likely to occur. Such programs require the force-deformation relation of such plastic hinges to be input. Deformation capacity of reinforced concrete columns is of paramount importance in PBD. The deformation capacity of a column can be expressed in terms of i) curvature ductility ii) displacement ductility and iii) drift. The ductility of reinforced concrete member can be determined from the moment curvature relationship $[3,4,5,6]$. The present paper describes the detailed procedure for computing the moment curvature relationship for RC columns as per IS 456:2000, for given column cross section and axial load and development of a program using VBA in Microsoft Excel for computing moment curvature values.
\end{abstract}

Keywords--- Moment Curvature, Performance based Design, Pushover Analysis, Performance Evaluation

\section{INTRODUCTION}

$\mathrm{T}$ HE relationship between the moment and curvature of reinforced concrete sections is an important parameter for carrying out inelastic analysis of RC framed structures. It is a measure of the strength, stiffness, ductility, and energy dissipation capacity of the structure. Theoretical moment curvature analysis of RC columns can be carried out using appropriate constitutive stress strain relations for concrete and steel.

The moments and curvatures associated with increasing flexural deformations of the column may be computed for various column axial loads by incrementing the curvature and satisfying the requirements of strain compatibility and equilibrium of forces[1]. The present study focuses on the moment curvature $(M-\phi)$ relation of a given column section. A computer program to generate moment-curvature relation of reinforced concrete columns is developed using stress-strain curves of concrete and steel as per IS 456:2000.

\section{STRESS STRAIN MODEL FOR CONCRETE}

Stress-strain curve of concrete is the basis of analysis and design of reinforced concrete sections. As specified by IS 456:2000, the characteristic and design stress-strain curves for concrete in flexural compression is depicted in Fig. 1. The maximum stress in the characteristic curve is restricted to $0.67 f_{c k}$. The curve is idealized as parabolic in the initial ascending portion up to a strain of 0.002 (where the slope becomes zero), and a straight line thereafter, at a constant stress level of $0.67 f_{c k}$, up to an ultimate strain of 0.0035 .For the purpose of limit state design a partial safety factor $\gamma_{c}=$ 1.5is applied. Thusthe design curve is obtained by dividing the ordinates of the characteristic curve $\gamma_{c}$ [Fig 1]. The design compressive stress $\mathrm{fc}$ is given as:

$$
f_{c}=\left\{\begin{array}{c}
0.446 f_{c k}\left[\left(\frac{2 \varepsilon_{c}}{\varepsilon_{c y}}\right)-\left(\frac{\varepsilon_{c}}{\varepsilon_{c y}}\right)^{2}\right], \quad \varepsilon_{c} \leq \varepsilon_{c y} \\
0.446 f_{c k}, \quad \varepsilon_{c}>\varepsilon_{c y}
\end{array}\right.
$$

$\varepsilon_{c y}=0.002$, yield strain. As observed from experiments, the stress strain curve descends after reaching the peak stress at the strain of $\varepsilon_{c y}$, but the code has idealized it as a flat region [2].

\section{StRESS StRain CURVE FOR REINFORCING STEEL}

The characteristic and design stress-strain curves, in tension and compression, as specified by IS 456:2000 for cold worked deformed bars (Fe 415 and Fe 500 grade steel) is as shown in Fig 2. The partial safety factor $\gamma_{s}$ is taken as 1.15 for ultimate limit state. The design yield strength $f_{y d}$ is obtained by dividing the specified yield strength $f_{y}$ by the partial safety factor and accordingly $f_{y d}=0.87 f_{y}$. However in the case of cold worked bars, there is no specific yield point. The transition from linear elastic behavior to inelastic behavior is assumed to occur at a stress level equal to $0.8 f_{y}$ in the characteristic curve and $0.8 f_{y d}$ in the design curve. The full design stress yield strength $0.87 f_{y}$ is assumed to correspond to a proof strain of $\varepsilon_{c y}$, that is, the design yield strain $\varepsilon_{y}$ is to be taken as $\frac{0.87 f_{y}}{E_{s}}+\varepsilon_{c y}$ as shown in Fig. 2. The coordinates of the salient points of the design stress-strain curve for Fe 415 grade of steel are listed in Table I. The design stress corresponding to any other value of strain can be obtained by interpolation [2].
Pramodini Naik Gaonkar, Lecturer, Civil Engineering, Government Polytechnic, Bicholim, Mayem, Goa, India.E-mail:prakrish13@gmail.com Dr. Satish A. Annigeri, Professor, Department of Civil Engineering, BVBCET, Vidyanagar, Hubballi, Karnataka, India. E-mail:satish@bvb.edu DOI:10.9756/BIJMMI.8147 


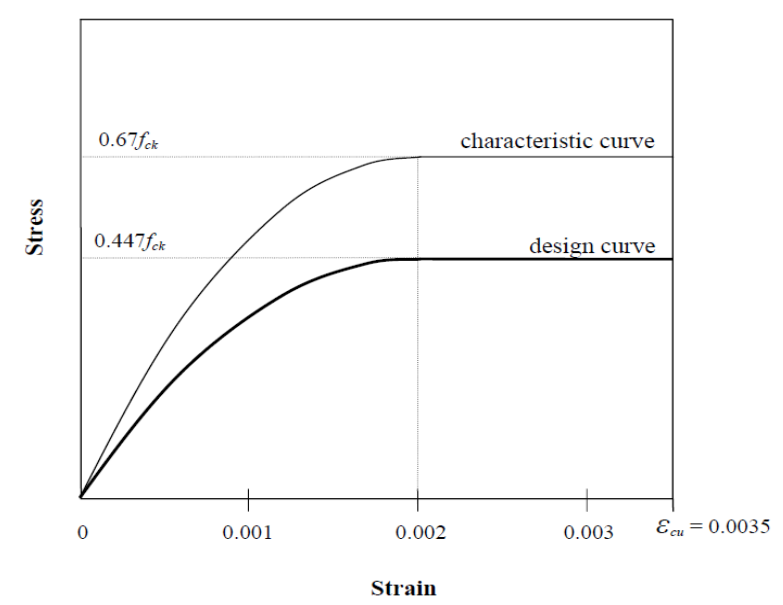

Figure 1: Characteristic and Design Stress-Strain Curves for Concrete in Flexural Compression

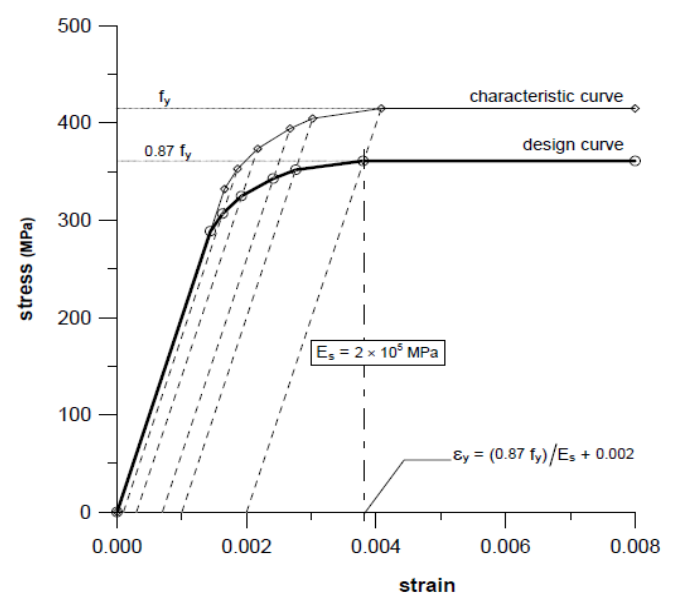

Figure 2: Characteristic and Design Stress-Strain Curves for Cold-Worked Steel

Table 1: Stress Strain Variation for Fe 415 Steel

\begin{tabular}{|l|l|}
\hline Strain & Stress $(\mathrm{MPa})$ \\
\hline 0.0000 & 0 \\
\hline 0.00144 & 288.7 \\
\hline 0.00163 & 306.7 \\
\hline 0.00192 & 324.8 \\
\hline 0.00241 & 342.8 \\
\hline 0.00276 & 351.8 \\
\hline$\geq 0.00380$ & 360.9 \\
\hline
\end{tabular}

\section{Moment CuRvature Relations}

Columns that are especially susceptible to axial-flexural, shear, and bond failure are potentially hazardous; as such displacements may lead to severe damage or collapse of a building. Lack of structural ductility is currently the most commonly observed seismic deficiency for existing RC buildings [7]. Moment-curvature relation is the important input parameter for a nonlinear analysis. The load-deformation behavior of a concrete section using nonlinear material stress-strain relationships can be computed using a moment-curvature analysis. A moment-curvature diagram plots the curvatures against corresponding moments, thus establishing the ductile capacity of a cross section $[8,9,10]$.

\section{A. Assumptions and Procedure}

Following assumptions are made:

- The strain distribution across the height of the section is linear, until failure. That is, a plane section remains plane after bending

- The tensile strength of concrete is ignored.

- The maximum compressive strain in concrete at the extreme compression fibre is taken as $\varepsilon_{c u}=0.0035$.

- The modulus of elasticity of concrete as per IS 456:2000 is taken as $E_{c}=5000 \sqrt{f_{c k}}$.

$f_{c k}=$ grade of concrete.For given section properties, extreme compression fibre strain and assumed neutral axis depth, $x u$, the moment curvature analysis of column can be carried using following steps/procedure $[1,11]$ :

1) Assume an initial value for compressive strain at extreme concrete fiber.

2) Assume neutral axis depth.

3) Calculate strain at centroid of each row of steel.

4) Find the corresponding stresses in steel and concrete for each value of strain using stress-strain models for concrete and steel.

5) Calculate force in steel bars, $S=\sum_{\mathrm{i}=1}^{\mathrm{n}} f_{s t i} A_{s t i}$

6) Where $S=$ total force in steel bars, $f_{\text {sti }}$ is the stress in steel and $A_{s t i}$ is the area of steel in the $i^{\text {th }}$ row of bars.

7) Calculate total force in compression concrete $C=$ $\sum_{i=1}^{n} f_{c} A_{c}$.

8) Where $C=$ is the total force in compression concrete, $f_{c}$ is the stress in concrete and $A_{-} C$ is the area of concrete.

9) Calculate the total axial force, $P_{i}=S+C$ by adding the force carried by steel and concrete.

10) Compare the axial force $P_{i}$ with the applied force, $P u$. If the difference is less than or equal to $0.5 \%$, then results are accepted and moment and curvature values are computed.

11) Otherwise adjust the neutral axis depth and return to step 3

12) Set the new maximum concrete strain and return to step 2.

13) Plot the moment-curvature values for the given applied load.

\section{B. Calculations for Column Section}

Table II gives the column design data for a square section of size $(500 \times 500) \mathrm{mm}$ and $P u=2984.11 \mathrm{kN}$. the detailed steps are outlined for carrying out moment curvature analysis based on the above given procedure. Since it is an iterative process a computer program has been developed using VBA based on the given steps and final values of curvature and moment are calculated for assumed values of strains. 
Table 2: Input Design Data for Column Section for Moment Curvature Analysis

\begin{tabular}{|l|l|}
\hline Description & Values \\
\hline Width of Column, B & $500 \mathrm{~mm}$ \\
\hline Total Depth of column, D & $500 \mathrm{~mm}$ \\
\hline Clear cover, Cc & $40 \mathrm{~mm}$ \\
\hline No of Rows of reinforcement, i or $\mathrm{n}$ & 5 \\
\hline No of Bars in Each row, R1 & 5 \\
\hline R2 & 2 \\
\hline R3 & 2 \\
\hline R4 & 2 \\
\hline R5 & 5 \\
\hline Diameter of bars in each row $(\mathrm{mm}), \mathrm{D} 1$ & 25 \\
\hline D2 & 25 \\
\hline D3 & 25 \\
\hline D4 & 25 \\
\hline D5 & 25 \\
\hline Area of steel in each row $\left(\mathrm{mm}^{2}\right)$, Ast1 & 2454.375 \\
\hline Ast2 & 981.75 \\
\hline Ast3 & 981.75 \\
\hline Ast4 & 981.75 \\
\hline Ast5 & 2454.375 \\
\hline External Load on the Column $\left(P_{u}\right)$ & $2984114 \mathrm{~N}$ \\
\hline Grade of concrete N/mm ${ }^{2}$ & 20 \\
\hline Grade of steel N/mm ${ }^{2}$ & 415 \\
\hline
\end{tabular}

Step 1: Assume concrete strain in extreme compression fiber $\varepsilon_{c}$ and N.A depth, $=k D$, where $\mathrm{k}=\mathrm{N}$.A coefficient.

Step 2: from the strain diagram find the strain in steel bars for each row as

$$
\varepsilon_{\mathrm{si}}=\varepsilon c\left(1-\frac{\mathrm{di}}{\mathrm{xu}}\right)
$$

Step 3: find the corresponding stress in steel bars at each row by referring stress-strain model for Fe 415 steel ( $f s i$ )

Step 4: find the corresponding stress in concrete at centroid of steel bars for each row $\left(f_{c c}^{\prime}\right)$

$$
f_{c c}^{\prime}=\left\{\begin{array}{c}
0.446 f_{c k}\left[\left(\frac{2 \varepsilon c}{\varepsilon_{c y}}\right)-\left(\frac{\varepsilon c}{\varepsilon c y}\right)^{2}\right], \quad \varepsilon_{c} \leq \varepsilon_{c y} \\
0.446 f_{c k}, \quad \varepsilon_{c}>\varepsilon_{c y}
\end{array}\right.
$$

Where, $\varepsilon_{c}$ is the extreme compression fiber strain, and $\varepsilon_{c y}=0.002$ is the yield strain.

Step 5: Calculate force in steel bars at each row $\left(F_{s i}\right)$

$$
F_{s i}=A_{s t i}\left(f_{s i}-f_{c c i}^{\prime}\right)
$$

When $\mathrm{k}<1$, i.e. when the N.A lies within the section, there exists tensile strains and compressive strains on LHS and RHS of the column section respectively (Fig.3a). Therefore the forces in steel bars are calculated as tensile force $\left(F_{\text {siT }}\right)$ with negative sign and compressive force $\left(F_{\text {siC }}\right)$ with positive sign. When $\mathrm{k}>1$, i.e. when the N.A lies outside the section there are only compressive strains in steel, therefore force carried by all the steel bars are compressive $\left(F_{s i C}\right)$.

Step 6: Calculate total force $S$ in steel bars (Fig. 3a)

$$
\begin{gathered}
\text { For } \mathrm{k}<1, S=\sum_{i=1}^{n} F_{s i C}-\sum_{i=1}^{n} F_{s i T} \\
\text { For } \mathrm{k}>1, S=\sum_{i=1}^{n} F_{S i C}
\end{gathered}
$$

Step 7: Calculate moment due to $S$ about the geometric centroidal axis of the column section $\left(M_{S}\right)$

$$
M_{s}= \begin{cases}S\left(\frac{D}{2}-a\right), & a \leq \frac{D}{2} \\ S\left(a-\frac{D}{2}\right), & a>\frac{D}{2}\end{cases}
$$

Where $a$ is the distance of force $S$ from extreme compression fiber of column section.

Step 8: Calculation of compressive force in concrete $\left(C_{1}\right)$

This depends on location of neutral axis from extreme compression fiber. Two cases arise: corresponding to location of neutral axis $x_{u}=k D$ lying within the section and neutral axis lying outside the section $(k \geq 1)$ :

Case i) Neutral axis lies within the section, that is, $x_{u}=$ $k D \leq D$ and therefore $k<1$ (Fig. 3b). in this the area of concrete under tension is ignored for calculating the force.

$$
C_{1}=\left\{\begin{array}{r}
0.446 f_{c k} B x_{u}\left[\frac{\varepsilon_{c}}{\varepsilon_{c y}}-\frac{1}{3}\left(\frac{\varepsilon_{c}}{\varepsilon_{c y}}\right)^{2}\right], \varepsilon_{c} \leq \varepsilon_{c y} \\
0.446 f_{c k} B x_{u}\left[\left(1-\frac{\varepsilon_{c y}}{\varepsilon_{c}}\right)+\frac{2}{3}\left(\frac{\varepsilon_{c y}}{\varepsilon_{c}}\right)\right], \varepsilon_{c} \leq \varepsilon_{c u}
\end{array}\right.
$$

Case ii) Neutral axis lies outside the section, that is, $x_{u}=k D \geq D$ and therefore $k \geq 1$

When $\varepsilon_{c} \leq \varepsilon_{c y},($ Fig. 3c)

$$
\begin{aligned}
C 1= & 0.446 f c k B x u\left\{\left[\frac{\varepsilon c}{\varepsilon c y}-\frac{1}{3}\left(\frac{\varepsilon c}{\varepsilon c y}\right)^{2}\right]\right. \\
& \left.-\frac{\varepsilon c l}{\varepsilon c}\left[\frac{\varepsilon c l}{\varepsilon c y}-\frac{1}{3}\left(\frac{\varepsilon c l}{\varepsilon c y}\right)^{2}\right]\right\}
\end{aligned}
$$

If $\varepsilon_{c} \leq \varepsilon_{c u}$, then

$$
\begin{array}{rl}
C_{1}=0.446 f c k & B D\left\{k\left(1-\frac{\varepsilon_{c y}}{\varepsilon_{c}}\right)+\left[1-k\left(1-\frac{\varepsilon_{c y}}{\varepsilon_{c}}\right)\right]\right. \\
- & \left.\frac{1}{3}\left[1-\frac{k\left(1-\frac{\varepsilon c y}{\varepsilon c}\right)}{k\left(\frac{\varepsilon_{c y}}{\varepsilon_{c}}\right)}\right]^{2}\left[1-k\left(1-\frac{\varepsilon_{c y}}{\varepsilon_{c}}\right)\right]\right\}
\end{array}
$$

Where, $\varepsilon_{c l}=$ strain at least compressed edge

Step 9: Calculation of moment of $C 1$ about the centroidal axis $(\mathrm{Mc})$

$$
M_{c}= \begin{cases}C_{1}\left[\bar{x}_{1}-\frac{D}{2}\right], & \bar{x}_{1}>\frac{D}{2} \\ C_{1}\left[\frac{D}{2}-\bar{x}_{1}\right], & \bar{x}_{1}<\frac{D}{2}\end{cases}
$$

Where $\bar{x}_{1}$ is the distance of $C_{1}$ from the neutral axis.

For case i) whencc $<\varepsilon_{c y}$, then

$$
\bar{x}_{1}=\frac{x_{u}\left[\frac{2}{3}-\frac{1}{4}\left(\frac{\varepsilon_{c}}{\varepsilon_{c y}}\right)\right]}{\left[1-\frac{1}{3}\left(\frac{\varepsilon_{c}}{\varepsilon_{c y}}\right)\right]}
$$


If $\varepsilon_{c} \leq \varepsilon_{c u}$, then

$$
\begin{gathered}
\bar{x}_{1}=x_{u}\left\{\frac{5}{12}\left(\frac{\varepsilon_{c y}}{\varepsilon_{c}}\right)^{2}+\left(1-\frac{\varepsilon_{c y}}{\varepsilon_{c}}\right)\left[\frac{\varepsilon_{c y}}{\varepsilon_{c}}+\frac{1}{2}\left(1-\frac{\varepsilon_{c y}}{\varepsilon_{c}}\right)\right]\right\} \\
/\left\{\left(1-\frac{\varepsilon_{c y}}{\varepsilon_{c}}\right)+\frac{2}{3}\left(\frac{\varepsilon_{c}}{\varepsilon_{c y}}\right)\right\}
\end{gathered}
$$

If $\varepsilon_{c} \leq \varepsilon_{c u}$, then

$$
\begin{aligned}
& \bar{x}_{1}=D\left\{k^{2}\left(1-\frac{\varepsilon_{c y}}{\varepsilon_{c}}\right)\left[1-\frac{1}{2}\left(1-\frac{\varepsilon_{c y}}{\varepsilon_{c}}\right)\right]+\left[1-k\left(1-\frac{\varepsilon_{c y}}{\varepsilon_{c}}\right)\right]\left[k\left(\frac{\varepsilon_{c y}}{\varepsilon_{c}}\right)-\left(\frac{1}{2}-\frac{k}{2}\left(1-\frac{\varepsilon_{c y}}{\varepsilon_{c}}\right)\right]\right.\right. \\
& -\frac{1}{3}\left[1-\frac{k\left(1-\frac{\varepsilon_{c y}}{\varepsilon_{c}}\right)}{k\left(\frac{\varepsilon_{c y}}{\varepsilon_{c}}\right)}\right]^{2}\left[1-k\left(1-\frac{\varepsilon_{c y}}{\varepsilon_{c}}\right)\right]\left[\frac{k \varepsilon_{c y}}{\varepsilon_{c}}-\left(\frac{3}{4}-\frac{3}{4} k\left(1-\frac{\varepsilon_{c y}}{\varepsilon c}\right)\right] /\left\{k\left(1-\frac{\varepsilon_{c y}}{\varepsilon_{c}}\right)+\left[1-k\left(1-\frac{\varepsilon_{c y}}{\varepsilon_{c}}\right)\right]\right.\right. \\
& \left.-\frac{1}{3}\left[1-\frac{k\left(1-\frac{\varepsilon_{c y}}{\varepsilon_{c}}\right)}{k\left(\frac{\varepsilon_{c y}}{\varepsilon_{c}}\right)}\right]^{2}\left[1-k\left(1-\frac{\varepsilon_{c y}}{\varepsilon_{c}}\right)\right]\right\}
\end{aligned}
$$

Step 10: Calculation of total force $P i$

$$
P i=C_{1}+S
$$

Step 11: Calculation of total moment $M i$

$$
M_{i}=M_{s}+M_{c}
$$

Step 12: Calculate N.A depth, $x_{u}=k D$, when $P_{i}=P_{u}$

For this we have to find

$$
\begin{aligned}
& P_{1}=\text { axial load when } k=\infty \\
& P_{2}=\text { axial load when } k=1
\end{aligned}
$$

To find $k$ apply the following conditions

$$
\begin{aligned}
& \text { if } P_{u}<P_{1} \text { decrease the assumed value of } k \\
& \text { if } P_{u}>P_{2} \text { then increase the assumed value of } k
\end{aligned}
$$

This iteration is carried out until $P_{i}=P_{u}$

Step 13: find the curvature, using the value of $x u$ for which $\left(P_{i}=P_{u}\right)$ as curvature $\phi=\frac{x_{u}}{\varepsilon_{c}}$

Step 14: Find the corresponding moment, $\left(M_{i}\right)$ using new value of $x_{u}$

Step 15: Repeat the steps for the next value of $\varepsilon_{c}$

Step 16: Plot the graph of moment vs. curvature

\section{RESULTS AND DISCUSSIONS}

The results are presented for the column section details given in table 2 in terms of moment curvature values for the different strains. The results are tabulated in table 3 and the graphical representation is given in Fig. 7.

Table 3: Moment Curvature Values for the Column Section

\begin{tabular}{|l|l|l|l|}
\hline Strain & Depth of NA(mm) & Moment in $\mathrm{kNm}$ & Curvature in $\mathrm{rad} / \mathrm{m}$ \\
\hline 0 & 0 & 0 & 0 \\
\hline 0.001 & 500 & 151.25 & 0.002 \\
\hline 0.0015 & 500 & 210.132 & 0.003 \\
\hline 0.0020 & 500 & 236.56 & 0.004 \\
\hline 0.0025 & 455 & 212.48 & 0.00549 \\
\hline 0.003 & 432.5 & 204.99 & 0.00693 \\
\hline 0.0035 & 417.5 & 221.37 & 0.00838 \\
\hline
\end{tabular}
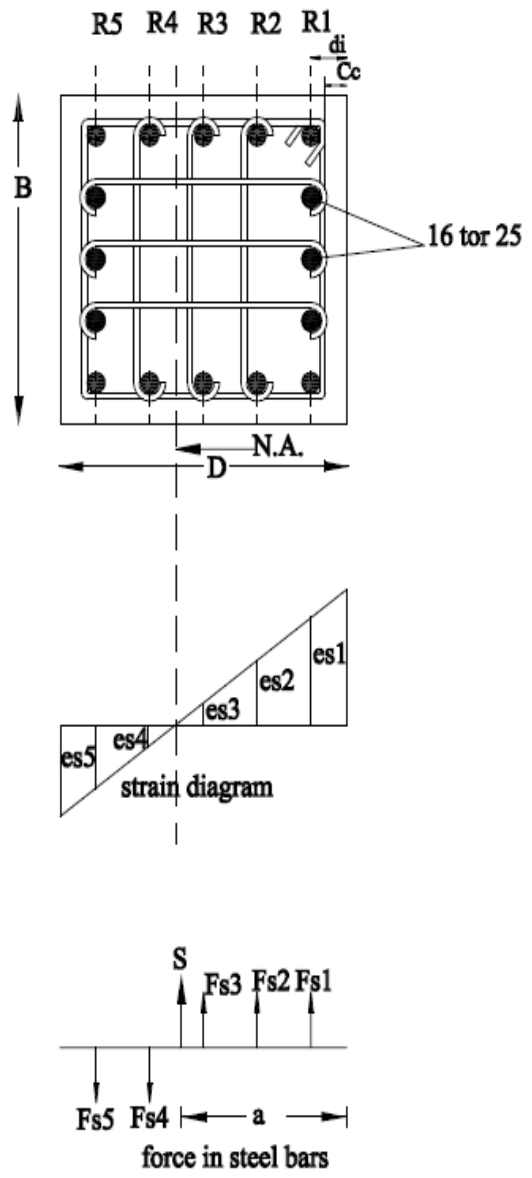

Figure 3: Strain Diagram for Steel
For case ii) when $\varepsilon_{c}<\varepsilon_{c y}$, then

$$
\begin{array}{r}
\bar{x}_{1}=x_{u}\left\{\left[\frac{2}{3}\left(\frac{\varepsilon_{c}}{\varepsilon_{c y}}\right)-\frac{1}{4}\left(\frac{\varepsilon_{c}}{\varepsilon_{c y}}\right)^{2}\right]-\left[\frac{2}{3}\left(\frac{\varepsilon_{c l}^{3}}{\varepsilon_{c} \varepsilon_{c y}}\right)-\frac{1}{4}\left(\frac{\varepsilon_{c l}^{4}}{\varepsilon c^{2} \varepsilon_{c y}^{2}}\right)\right]\right\} \\
/\left\{\left[\left(\frac{\varepsilon_{c}}{\varepsilon_{c y}}\right)-\frac{1}{3}\left(\frac{\varepsilon_{c}}{\varepsilon_{c y}}\right)^{2}\right]-\left[\left(\frac{\varepsilon_{c l}^{2}}{\varepsilon_{c} \varepsilon_{c y}}-\frac{1}{3}\left(\frac{\varepsilon_{c l}^{3}}{\varepsilon_{c} \varepsilon_{c y}^{2}}\right)\right]\right\}\right]
\end{array}
$$




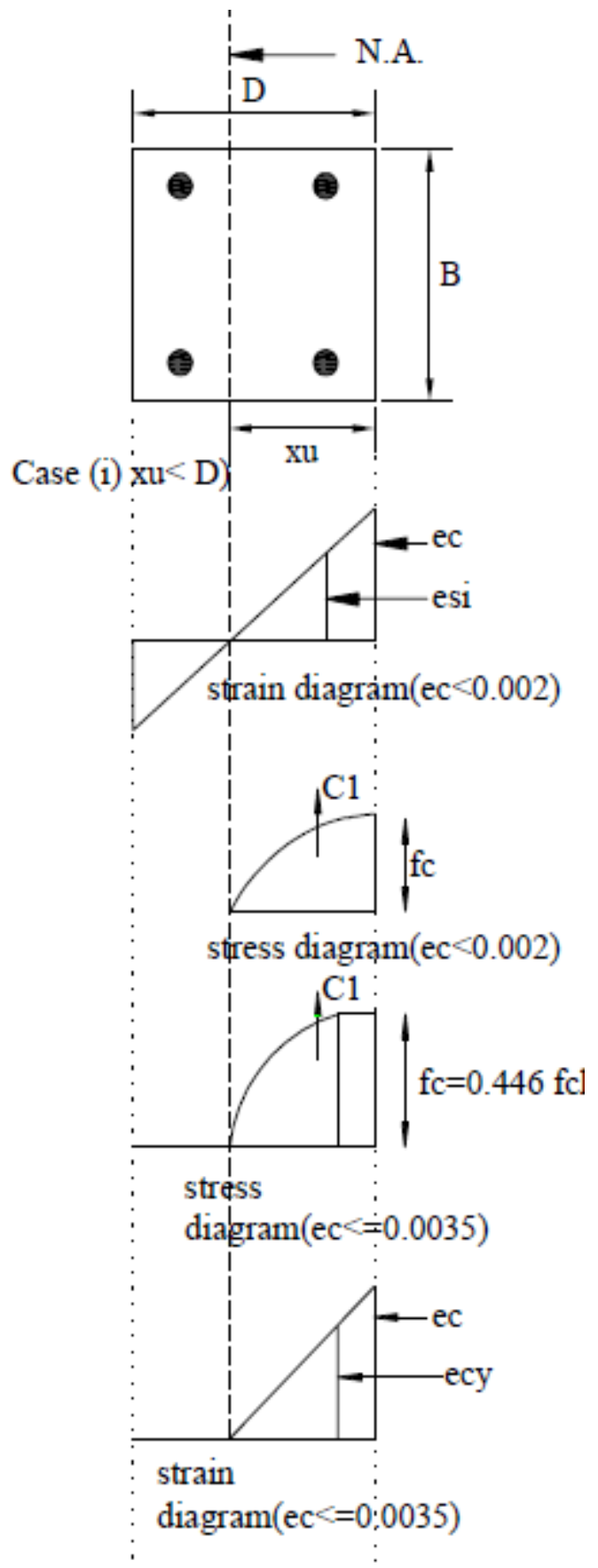

Figure 4: Stress Strain Diagram for Concrete, Case (i)

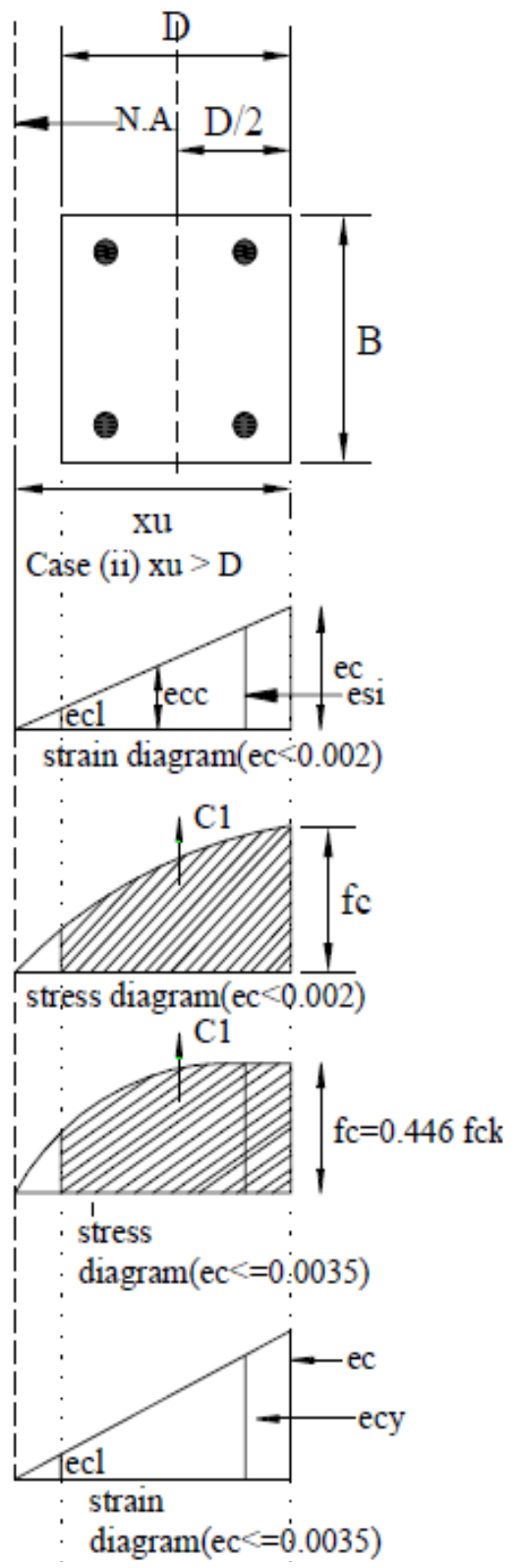

Figure 5: Stress Strain Diagram for Concrete, Case (ii)

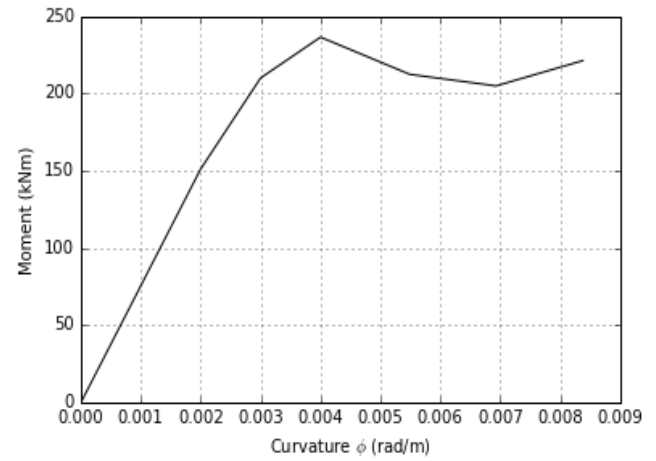

Figure 6: Moment Curvature Graph for the Column Section for $\mathrm{P}_{\mathrm{u}}=2984.1 \mathrm{kN}$ 


\section{CONCLUSION}

The knowledge on the moment curvature relationships of the critical sections of reinforced concrete members is essential for a realistic determination of the behaviour of flexural members against earthquake forces. In this study by using IS stress-strain models for unconfined concrete and Fe 415 steel, analytical moment-curvature relationships are obtained for reinforced concrete column section subjected to axial load and flexural moment. These moment curvature values of column cross section can be used for generating moment rotation values, as an input for defining nonlinear hinges for carrying out pushover analysis. The results of pushover analysis with user defined hinges can be used for evaluating the performance of columns against the anticipated earthquakes in particular seismic zone.

\section{REFERENCES}

[1] R. Park and T. Pauley, "Reinforced concrete structures", New York, NY, USA; John Wiley \& Sons, 1975.

[2] "IS: 456-2000 Plain and reinforced concrete-code of practice", New Delhi: Bureau of Indian Standards, 2000.

[3] J. Browning, Y.R. Li, A. Lynn and J.P. Moehle, "Performance assessment for a reinforced concrete frame building", Earthquake Spectra, Vol. 16, No. 3, Pp. 541-555, 2000.

[4] P. Fajfar, "A nonlinear analysis method for performance based seismic design”, Earthquake Spectra, Vol.16, No. 3, Pp. 573-592, 2000.

[5] J.M. Bracci, S.K. Kunnath and A.M. Reinhorn, "Seismic performance and retrofit evaluation for reinforced concrete structures", J. Struc. Engg. ASCE, Vol. 123, No. 1, Pp. 3-10.

[6] A. Ghobarah, "Performance-based design in earthquake engineering: state of development", Engineering Structures, Vol. 23, Pp. 878-884, 2001.

[7] FEMA-356, "Federal Emergency Management Agency", Prestandard and commentary for the seismic rehabilitation of buildings, Washington D.C., 2005.

[8] M. Inel and H.B. Ozmen, "Effects of plastic hinge properties in nonlinear analysis of reinforced concrete buildings", EngStruct, Vol. 28, Pp. 1494-502, 2006.

[9] A.K. Jain, "Introduction to Non-linear analysis of building frames", IIT Roorkee, 2008.

[10] A. Eslami and H.R. Ronagh, "Effect of elaborate plastic hinge definition on the pushover analysis of reinforced concrete buildings", 2014.

[11] A.K. Jain, "Dynamics of Structure with MATLAB applications", Pearson, India, 2016. 